\title{
Application of paleolimnological methods in study of ecosystem transformations in reservoirs
}

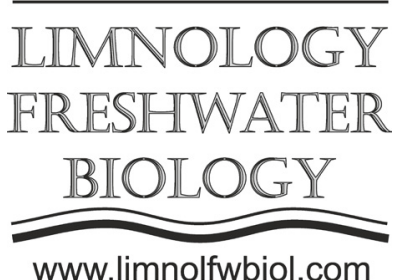

\author{
Razumovsky L.V.* \\ Water Problems Institute of the Russian Academy of Sciences, Gubkina str. 3, Moscow, 119333, Russia
}

\begin{abstract}
The paper is devoted to the assessment of long-term environmental changes in artificial reservoirs. The novelty of the research consists in combnation two traditional methods: analysis of diatomic complexes from sediment columns, which usually used in paleolimnology, and analysis of phytoplankton complexes, which commonly used in biomonitoring. In addition to combining these two methodological approaches, a correlation was made between hydrobiological and hydrochemical observations in reservoirs. This allowed us to get a qualitatively new level of information about the development of reservoirs as a single ecosystem. The degree and direction of transformation of their ecosystems under the influence of integrated anthropogenic load was reliably estimated. The paper uses the author's method of graphical analysis of taxonomic proportions in diatom complexes and the principle of unification of bioindication methods.
\end{abstract}

Keywords: reservoirs, anthropogenic load, phytoplankton, diatom complexes

\section{Introduction}

To date, there are more than 2 thousand artificial ponds on the territory of Russia that fall under the category of reservoirs. The oldest of them were formed more than 70-75 years ago (Ivankovskoe, Klyazminskoe, Rybinskoe, etc.), as a result of the receipt of industrial and domestic wastewater at the bottom of most of them formed sediments with high concentrations of pollutants. At the same time, in the deepest parts of reservoirs, the size of these deposits is comparable with the size of of the late Holocene lake deposits.

\section{Material and methods}

The structure and volume of the primary material were more than 300 hydrochemical and 300 phytoplankton samples taken in the water area of three reservoirs: Ivankovsky, Rybinsky and Klyazminsky. Sediment columns were selected in all reservoirs (160 samples). Diatomic complexes were studied in layers in samples from the buttom sediment columns and the chemical composition of precipitation was analyzed.

Diatomic analysis was chosen as the main research method. In addition to the traditional forms of diatomic analysis, two author's methods were used: the method of graphical analysis (MGA) and the unification of bioindication methods (UBM) (Moiseenko, Razumovskiy, 2009; Razumovskiy, Moiseenko, 2009). The saprobity index (S) for Sladecek (Slàdeček, 1973) was calculated for complex monitoring of reservoirs for phytoplankton and diatom complexes from buttom sediments.

\section{Results and discussions}

For the ecosystems of the Ivankovsky and Rybinsk reservoirs, the processes of reversible transformations in phytoplankton complexes, which are overlaid with seasonal and climatic variability, were confirmed.

The main scenarios of taxonomic proportions transformation in phytoplankton associations were established for the water area of the Klyazma reservoir using the MGA. They were caused by the impact of water from the Moscow River and the annual decrease in the reservoir level, with planned water consumption. In all cases, significant reliability of information was established for the MGA. This is determined by the reproducibility of the obtained results. Despite the different configuration, location and hydrological regime, a number of similar and alarming trends were identified for all reservoirs.

With the help of UBM, pronounced saprobization and accumulation of organic matter was established in the coastal zones of the Rybinsk and Ivankovsky reservoirs. In the bottom sediments of the Klyazminsky reservoir revealed a regular increase in the level of suprabasal. This is due to a non-linear growth in the number of vacationers and an increase in anthropogenic load. 
The second significant pattern is the pronounced accumulation of $\mathrm{Cu}, \mathrm{Zn}$ and other heavy metals in the coastal zones of all three reservoirs. Such violations of environmental well-being could cause the irreversible changes in the system.

For all three reservoirs (Ivankovsky, Rybinsky and Klyazminsky), the rates of pollutants accumulation in the water and their genesis were determined. The general regularity of differentiation of pollution processes in the central parts of the water area and in the shallow coastal zone of reservoirs were established.

\section{Conclusions}

1. The studied reservoirs are characterized by the process of pollution differentiation in the central parts of the water area and in the coastal zone.

2. General regularities of integral sedimentation zones location differ significantly in lakes and reservoirs.
3. The method of graphical analysis (MGA) allows us to more objectively establish seasonal and long-term transformation in ecosystems of water reservoirs.

\section{Acknowledges}

The work was supported by RFBR grant №17-05-00673

\section{References}

Moiseenko T.I., Razumovskiy L.V. 2009. A new technique for reconstructing the cation-anion balance in lakes by diatom analysis. Doklady Biological Sciences 427(1): 325-328.

Razumovskiy L.V., Moiseenko T.I. 2009. Estimation of spatiotemporal transformations of lake ecosystems by the method of diatom analysis. Doklady Biological Sciences 429(3): 514-517.

Slàdeček V. 1973. System of water quality from biological point of view. Archiv für Hydrobiologie-BeiheftErgebnisse der Limnologie 7(I-IV): 1-218. 